\title{
PERIOPERATIVE OUTCOMES OF LAPAROSCOPIC HYSTERECTOMY: COMPARISON WITH ABDOMINAL, VAGINAL, AND ROBOT-ASSISTED SURGICAL APPROACHES
}

\section{SlavchoT. Tomov, Grigor A. Gortchev, Latchesar S. Tantchev, Todor I. Dimitrov, Chavdar A. Tzvetkov, Savelina L. Popovska ${ }^{1}$}

Gynecologic Oncology Clinic, Department of Obstetrics \& Gynecology, Division of Minimally Invasive Gynecologic Surgery, Medical University - Pleven ${ }^{1}$ Department of General and Clinical Pathology, Medical University - Pleven, Bulgaria

\section{Corresponding Author:}

Slavcho T. Tomov

Gynecologic Oncology Clinic

8A, Georgi Kochev str.

Pleven, 5800

Bulgaria

e-mail:slavcho_tomov@yahoo.de

Received: March 23, 2015

Revision received: March 31, 2015

Accepted: May 18, 2015

\author{
Summary
}

Selection of an appropriate surgical method for hysterectomy in an individual patient is currently an issue that remains open and debatable. This study aimed to analyze perioperative outcomes in gynecologic patients who underwent laparoscopic hysterectomy at a single institution during a 6-year period and to compare the data for simple hysterectomy patients treated with different surgical approaches. The study included a retrospective analysis of demographics, pre- and post-operative characteristics of 1,023 patients, operated on using four types of simple hysterectomy approaches: 635 laparoscopic hysterectomies (62.1\%), 289 total abdominal hysterectomies $(28.3 \%), 45$ total vaginal hysterectomies $(4.4 \%)$, and 54 robotic-assisted hysterectomies $(5.3 \%)$. For the laparoscopic hysterectomy group, the mean operative time was shorter as compared to the abdominal and vaginal hysterectomy groups $(p<0.05)$, as well as a significantly shorter hospital length-of-stay when compared to the abdominal, robotic or vaginal hysterectomy groups $(p<0.05)$. Regression analysis revealed significant linear correlation between operative time and body-mass index of laparoscopic hysterectomy patients $\left(\mathrm{R}^{2}=0.008 ; p=0.026\right)$. Complications emergence and hemotransfusion often prolonged the mean operative time significantly by 17.8 $\min (p=0.002)$ and $15.5 \mathrm{~min}$, respectively $(p<0.001)$. The rate of major complications was significantly higher in the laparoscopic vs. abdominal groups $(p<0.05)$. Clinical outcomes in patients operated on with laparoscopic hysterectomy were better than in those operated with total abdominal and vaginal hysterectomy in terms of operative time and hospital length-of-stay. Prospective randomized multi-center studies would be desirable to further define the place of the modern minimally invasive hysterectomy approaches.

Key words: laparoscopic hysterectomy, peri-operartive outcome, comparative analysis surgical approaches

\section{Introduction}

Kurt Semm was the first to describe laparoscopic assistance during vaginal hysterectomy in 1984. In 1989, Harry Reich presented the technique of the first laparoscopic hysterectomy $(\mathrm{LH})[1,2]$. Since then, LH has been the subject of series of studies. 
Most of these studies demonstrated that, compared with the total abdominal hysterectomy (TAH), LH has certain advantages: faster recovery, diminished post-operative pain, and better cosmetic results $[3,4]$. Cost analysis over the last few years has indicated that the average direct costs for $\mathrm{LH}$ and TAH are rather similar. Mean total patient costs are significantly lower for LH as compared to TAH $[5,6]$.

Despite the progress in laparoscopic techniques for hysterectomy, TAH is still the most frequently used surgical approach in many countries, and the LH rate remains comparatively low, ranging from $3 \%$ to $24 \%$ only [7-9]. Recent data from the US show that the frequency of hysterectomies depending on the type of access is approximately $66 \%$ for the abdominal, $22 \%$ for the vaginal, and $12 \%$ for the laparoscopic approach [10]. More recently, with the introduction of robotic-assisted surgery for hysterectomy, some centers have even reported decreasing rates of traditional laparoscopic hysterectomy [11].

With the introduction of the minimally invasive surgical (MIS) techniques in gynecological practice, the selection of the appropriate surgical method of hysterectomy for an individual patient remains open and debatable. The primary objective of this study was to investigate the perioperative factors and clinicopathologic outcomes in gynecologic patients who underwent $\mathrm{LH}$ at a single institution during a 6year period and to compare the contemporaneous data analyzed for patients who were treated with $\mathrm{TAH}$, total vaginal hysterectomy (TVH), and robotic-assisted hysterectomy (RAH) procedures.

\section{Materials and Methods}

This study included all the simple hysterectomies performed at a single institution between April 2004 and April 2010. Two skilled surgeons (gynecologic oncologists) performed all the abdominal and vaginal hysterectomies. The surgeons were trained to perform laparoscopic and robotic-assisted gynecologic surgeries at the European Institute of Telesurgery in Strasbourg, France.

Permission for conducting the study was received from the local Institutional Review Board. All procedures followed were in accordance with the ethical standards of the responsible committee on human experimentation (institutional and national) and with the Helsinki Declaration of 1975, as revised in 2000. Informed consent was obtained from all patients for being included in the study.

Data were collected retrospectively from the patients' medical records (hard charts and electronic records). The abstracted data included the following demographics, pre-operative and peri-operative characteristics of patients: age, indications for surgery, body mass index (BMI), previous abdominal operations, mode of delivery (vaginal or cesarean section), number of the vaginal childbirths, operative time, uterine size, hospital length-of-stay (LOS), post-operative hemoglobin and hematocrit levels, and complications. To assess the parameters with probable impact on the operative time, the following variable factors were investigated: age, indication for surgery, year of surgery performance, delivery mode, and number of vaginal deliveries, uterine size, BMI, previous operation, accompanying operative procedure, complications, hemotransfusion, and conversion.

The operative time was measured in minutes as the interval from skin incision of the anterior abdominal wall ( $\mathrm{LH}, \mathrm{TAH}$, and RAH) or vaginal mucosa $(\mathrm{TVH})$ to placement of the last skin $(\mathrm{LH}$, $\mathrm{TAH}$, and RAH) or mucosa stitch (TVH). Uterus size was determined according to the size of pregnant uterus in weeks of gestation $(\mathrm{GW})$, the categories being: normal uterus and enlarged uterus, respectively, from $4 \mathrm{GW}$ up to and over 24 $\mathrm{GW}$. The values of the hemoglobin $(\mathrm{g} / \mathrm{L})$ and hematocrit on the first post-operative day were examined. The LOS (in days) was determined as the time period from the date of operation to the date of discharge. The complications were defined as major or minor, and as intra-operative and post-operative. Post-operative complications were reported up to 4 weeks after the surgery. Bleeding that required re-operation as well as injury of the intestines, ureters, bladder and large vessels were defined as major complications. Operative wound complications, hematomas of the anterior abdominal wall, vaginal cuff cellulitis and bleedings that did not require reoperations were defined as minor complications. The blood transfusions performed intraoperatively and to the $24^{\text {th }}$ post-operative hour were also registered. When it was necessary to switch from laparoscopic or robotic-assisted hysterectomy to abdominal during the operation, the case was assessed as conversion.

The laparoscopic hysterectomies performed included three sub-types of hysterectomies 
according to the definitions offered by Reich and Roberts and modified by Johnson et al as: i) laparoscopic-assisted vaginal hysterectomy (LAVH), ii) LH with uterine artery ligation [LH(a)], and iii) total laparoscopic hysterectomy (TLH) $[12,13]$. The technique of LAVH that we utilized corresponded to type IB3 laparoscopic hysterectomy [in accordance with the classification of the American Association of Gynecologic Laparoscopists (AAGL)], and those of LH(a) and TLH - to type IIB3 (AAGL) and type IVE (AAGL), respectively [14]. Further details of our surgical protocol for application of the da Vinci ${ }^{\circledR} \mathrm{S}$ robotic system for hysterectomy is similar to the one recently described [15]. The technique of the TAH and TVH procedures was fairly similar to that described in the $9^{\text {th }}$ edition of Te Linde's Operative Gynecology [16].

Vaginal surgery was offered to patients with uterine prolapse, at least one vaginal birth, unenlarged uterus and without prior abdominal surgery. For large and very-large uteri, TAH was recommended. In all the other cases, MIS was offered, and RAH was the preferred approach in malignant pathology and high BMI cases. The advantages and disadvantages of the various accesses were discussed with all patients, and their desires were taken into considerations.

Data were entered and processed with the statistical package IBM SPSS Statistics 19.0. The $p$-value with $<0.05$ was chosen as a significance level, to reject the null hypothesis. Descriptive, variation, alternative, and graphical analysis, Chi-square test, Fisher's exact test, Student $t$-test, non-parametric test of Kruscal-Wallis, MannWhitney U test and regression analysis were used.

\section{Results}

Four types of simple hysterectomies were performed on a total of 1,023 gynecologic patients during the 6-year period of the study. The distribution of the cases was as follows: $\mathrm{LH}=635$ $(62.1 \%), \mathrm{TAH}=289(28.3 \%), \mathrm{TVH}=45(4.4 \%)$, and $\mathrm{RAH}=54(5.3 \%)$. Within the LH sub-group, the distribution of the cases was as follows: $\mathrm{LAVH}=168(16.4 \%), \mathrm{LH}(\mathrm{a})=435(42.5 \%)$, and $\mathrm{TLH}=32(3.1 \%)$. Basic pre-operative characteristics of the patients according to the type of operation are presented in Table 1. The most common indication for surgery in the $\mathrm{LH}$ cohort ( $\mathrm{n}=635$ ) was uterine myoma -462 cases (72.8\%). Highest median BMI was documented in patients who underwent RAH $\left(27.3 \mathrm{~kg} / \mathrm{m}^{2}\right)$ and
TVH $\left(27.3 \mathrm{~kg} / \mathrm{m}^{2}\right)$ procedures, as compared to the LH group $\left(24.2 \mathrm{~kg} / \mathrm{m}^{2} ; p<0.001\right)$ and the TAH group $\left(25.4 \mathrm{~kg} / \mathrm{m}^{2} ; p=0.002\right)$. Patients in the RAH group had had a relatively larger number of previous operations $(44.4 \%)$ than all the other groups. This was found to be statistically significant as compared to TVH $(22.2 \%$; $p=0.033)$ (Table 1).

The basic intra- and postoperative characteristics of the types of hysterectomies performed are shown in Table 2. The mean operative time in the LH group was as compared to that of the TAH and TVH groups $(p<0.05)$, and the hospital LOS was significantly shorter as compared to the TAH, RAH or TVH group $(p<0.05)$. The mean hemoglobin level on the first post-operative day with LH was significantly higher than the one found in the TAH and lower than that of the TVH group $(p<0.05)$. (Table 2 ) Basic peri-operative characteristics in the subgroup of LH are presented in Table 3. The TLH group had a significantly shorter operative time as compared to the LAVH and LH(a) sub-groups. Hemoglobin and hematocrit levels in the subgroups were comparable (Table 3 ).

The analysis of factors with possible impact on the operative time of $\mathrm{LH}$ revealed that uterine prolapse as an indication for surgery, and enlarged as $16 \mathrm{GW}$ to $20 \mathrm{GW}$ uterus, significantly prolonged the time $(p<0.05)$. Regression analysis revealed a statistically significant linear correlation between the operative time and BMI of patients who underwent $\mathrm{LH} \quad\left(\mathrm{R}^{2}=0.008\right.$; $p=0.026$ ). Complications emergence and hemotransfusion often prolonged the mean operative time significantly: by $17.8 \mathrm{~min}$ $(p=0.002)$ and $15.5 \mathrm{~min}(p<0.001)$, respectively. History of conization resulted in a significant reduction in the mean operative time $(2.8 \mathrm{~min}$; $p<0.05)$. As shown in Figure 1 , regression analysis revealed a linear relationship between the operative time and each subsequent year of LH procedures, when compared to the year of the first operation performed by the same team $\left(\mathrm{R}^{2}=0.144 ; \quad p<0.001\right)$. All other parameters studied did not significantly affect the duration of LH $(p>0.05)$.

Table 4 shows the rate of complications according to the surgical type of hysterectomies performed. The analysis revealed no significant correlation between the type of hysterectomy, respective to the sub-groups of $\mathrm{LH}$ and the appearance of complications $(p>0.05)$. The rate of major complications was significantly higher 
Table 1. Patients' preoperative characteristics according to the type of hysterectomy procedures

\begin{tabular}{|c|c|c|c|c|}
\hline \multirow{2}{*}{ Characteristics } & $\mathbf{L H}$ & TAH & TVH & RAH \\
\hline & $(n=635)$ & $(n=289)$ & $(n=45)$ & $(n=54)$ \\
\hline \multicolumn{5}{|l|}{ Age (year) } \\
\hline Median $\quad(\mathrm{IQR})^{\mathrm{a}}$ & $45(41-49)$ & $46(42-51)$ & $60(55.5-72)$ & $53.5(43.5-64.2)$ \\
\hline$p$-value $^{\mathrm{b}}$ comparisons with RAH & $<0.001$ & $<0.001$ & 0.001 & \\
\hline Comparisons with LH & & 0.004 & $<0.001$ & \\
\hline Comparisons with TAH & & & $<0.001$ & \\
\hline \multicolumn{5}{|l|}{ Indications for surgery, n (\%) } \\
\hline Myoma of the uterus & $462(72.8)$ & $201(69.6)$ & $6(13.3)$ & $11(20.4)$ \\
\hline Cervical carcinoma in situ & $75(11.8)$ & $14(4.8)$ & $0(0)$ & $10(18.5)$ \\
\hline Adenomyosis & $9(1.4)$ & $3(1.0)$ & $0(0)$ & $2(3.7)$ \\
\hline Endometrial carcinoma & $19(3.0)$ & $18(6.2)$ & $0(0)$ & $22(40.7)$ \\
\hline Ovarian carcinoma & $4(0.6)$ & $9(3.1)$ & $0(0)$ & $0(0)$ \\
\hline Uterine prolapse & $8(1.3)$ & $0(0)$ & $38(84.4)$ & $0(0)$ \\
\hline Atypical endometrial hyperplasia & $14(2.2)$ & $6(2.1)$ & $1(2.2)$ & $2(3.7)$ \\
\hline Endometrial polyposis & $7(1.1)$ & $1(0.3)$ & $0(0)$ & $1(1.9)$ \\
\hline Microinvasive cervical carcinoma & $11(1.7)$ & $3(1.0)$ & $0(0)$ & $1(1.9)$ \\
\hline Bening ovarian tumor & $26(4.1)$ & $34(11.8)$ & $0(0)$ & $3(5.6)$ \\
\hline \multicolumn{5}{|l|}{ BMI $\left(\mathrm{kg} / \mathrm{m}^{2}\right)$} \\
\hline 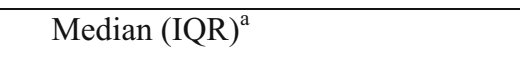 & $24.2(21.4-27)$ & $25.4(22.9-30.1)$ & $27.3(23.3-30.3)$ & $27.3(23.9-34.8)$ \\
\hline$p$-value $^{\mathrm{b}}$ comparisons with RAH & $<0.001$ & 0.002 & 0.116 & \\
\hline Comparisons with LH & & $<0.001$ & $<0.001$ & \\
\hline Comparisons with TAH & & & 0.299 & \\
\hline \multicolumn{5}{|l|}{ Prior operations, n (\%) } \\
\hline 1 Laparotomy & $192(30.3)$ & $78(27.0)$ & $9(20.0)$ & $19(35.2)$ \\
\hline 2 Laparotomies & $23(3.6)$ & $16(5.5)$ & $0(0)$ & $4(7.4)$ \\
\hline$\geqslant 3$ Laparotomies & $8(1.3)$ & $3(1.0)$ & $0(0)$ & $0(0)$ \\
\hline Laparoscopies & $11(1.7)$ & $1(0.3)$ & $1(2.2)$ & $1(1.9)$ \\
\hline Total & $234(36.9)$ & $98(33.9)$ & $10(22.2)$ & $24(44.4)$ \\
\hline$p$-value ${ }^{\mathrm{c}}$ comparisons with RAH & 0.306 & 0.163 & 0.033 & \\
\hline Comparisons with LH & & 0.416 & 0.054 & \\
\hline Comparisons with TAH & & & 0.127 & \\
\hline
\end{tabular}

${ }^{\mathrm{a}} \mathrm{IQR}=$ Inter Quartile Range (25 and 75 percentiles)

${ }^{\mathrm{b}} p$-value from two independent samples (Mann-Whitney $\mathrm{U}$ test)

' $p$-value from Chi-square test or Fisher's exact test

Abbreviations: $\mathrm{LH}=$ laparoscopic hysterectomy; $\mathrm{TAH}=$ total abdominal hysterectomy; $\mathrm{TVH}=$ total vaginal hysterectomy; $\mathrm{RAH}$ $=$ robotic-assisted hysterectomy; $\mathrm{BMI}=$ body mass index 
Table 2. Perioperative characteristics of patients in the types of hysterectomies

\begin{tabular}{lllll}
\hline \multirow{2}{*}{ Factors } & LH $(\mathrm{n}=635)$ & TAH $(\mathrm{n}=289)$ & TVH $(\mathrm{n}=45)$ & RAH $(\mathrm{n}=54)$ \\
\cline { 2 - 5 } & $\overline{\mathrm{X}} \pm \mathrm{SD}$ & $\overline{\mathrm{X}} \pm \mathrm{SD}$ & $\overline{\mathrm{X}} \pm \mathrm{SD}$ & $\overline{\mathrm{X}} \pm \mathrm{SD}$ \\
\hline Operative time (min) & $76,58^{\mathrm{a}} \pm 26,61$ & $94,01^{\mathrm{b}} \pm 26,71$ & $97,78^{\mathrm{b}} \pm 30,89$ & $85,00^{\mathrm{a}} \pm 34,79$ \\
\hline Hospital length-of-stay (days) & $3,14^{\mathrm{a}} \pm 1,23$ & $4,66^{\mathrm{b}} \pm 1,96$ & $5,29^{\mathrm{c}} \pm 1,42$ & $3,76^{\mathrm{d}} \pm 1,68$ \\
\hline Post-operative hemoglobin (g/L) & $111,41^{\mathrm{a}} \pm 13,15$ & $109,98^{\mathrm{bc}} \pm 12,82$ & $116,13^{\mathrm{bd}} \pm 14,16$ & $111,74^{\mathrm{acd}} \pm 14,81$ \\
\hline Post-operative hematocrit (1/L) & $0,32^{\mathrm{a}} \pm 4,22$ & $0,32^{\mathrm{a}} \pm 4,31$ & $0,33^{\mathrm{a}} \pm 4,77$ & $32,02^{\mathrm{a}} \pm 4,22$ \\
\hline
\end{tabular}

$*=$ the identical letters horizontally mean that there is no significant difference, and the presence of $\operatorname{such}(p<0.05)$ is marked by the different letters (such as a, b, c)

Abbreviations: $\mathrm{LH}=$ laparoscopic hysterectomy; $\mathrm{TAH}=$ total abdominal hysterectomy; $\mathrm{TVH}=$ total vaginal hysterectomy;

$\mathrm{RAH}=$ robotic-assisted hysterectomy

Table 3. Pre-, intra- and postoperative characteristics of patients in the laparoscopic hysterectomies sub-groups

\begin{tabular}{llll}
\hline \multirow{2}{*}{ Factors } & LAVH (n=168) & LH(a) (n=435) & TLH (n=32) \\
\cline { 2 - 4 } & $\overline{\mathrm{X}} \pm \mathrm{SD}$ & $\overline{\mathrm{X}} \pm \mathrm{SD}$ & $\overline{\mathrm{X}} \pm \mathrm{SD}$ \\
\hline Age (year) & $46,24^{\mathrm{a}} \pm 6,56$ & $45,20^{\mathrm{a}} \pm 6,25$ & $45,31^{\mathrm{a}} \pm 8,21$ \\
\hline BMI $\left(\mathrm{kg} / \mathrm{m}^{2}\right)$ & $25,05^{\mathrm{a}} \pm 4,27$ & $24,33^{\mathrm{a}} \pm 3,81$ & $24,55^{\mathrm{a}} \pm 5,00$ \\
\hline Operative time (min ) & $89.6 \pm 31.5^{\mathrm{a}}$ & $72.4 \pm 22.7^{\mathrm{b}}$ & $65.8 \pm 25.3^{\mathrm{c}}$ \\
\hline Hospital length -of -stay (days) & $3.51 \pm 1.69^{\mathrm{a}}$ & $3.0 \pm 1.01^{\mathrm{bc}}$ & $3.03 \pm 0.47^{\mathrm{a}, \mathrm{c}}$ \\
\hline Post-operative hemoglobin (g/L) & $109.9 \pm 14.4^{\mathrm{a}}$ & $111.5 \pm 12.4^{\mathrm{a}}$ & $117.7 \pm 14.5^{\mathrm{b}}$ \\
\hline Post-operative hematocrit (1/L) & $0.31 \pm 4.63^{\mathrm{a}}$ & $0.32 \pm 4.04^{\mathrm{b}, \mathrm{c}}$ & $0.33 \pm 4.28^{\mathrm{a}, \mathrm{c}}$ \\
\hline
\end{tabular}

* - the identical letters horizontally mean that there is no significant difference, and the presence of such $(p<0.05)$ is marked by the different letters (such as a, b, c)

Abbreviations: $\mathrm{LAVH}$ = laparoscopic-assisted vaginal hysterectomy; LH(a) = laparoscopic hysterectomy "type a"; $\mathrm{TLH}=$ total laparoscopic hysterectomy

Table 4. Types of complications in patients who underwent hysterectomy procedures with different surgical approaches

\begin{tabular}{llllll}
\hline Complications, $\mathbf{n}(\%)$ & $\begin{array}{l}\text { LH } \\
(\mathrm{n}=635)\end{array}$ & $\begin{array}{l}\text { TAH } \\
(\mathrm{n}=289)\end{array}$ & $\begin{array}{l}\text { TVH } \\
(\mathrm{n}=45)\end{array}$ & $\begin{array}{l}\text { RAH } \\
(\mathrm{n}=54)\end{array}$ & $\begin{array}{l}\text { Total } \\
(\mathrm{n}=1,023)\end{array}$ \\
\hline Major complications & $14(2.2)$ & $4(1.3)$ & 0 & $1(1.9)$ & $19(1.9)$ \\
\hline Urinary bladder injury & $5(0.8)$ & $1(0.3)$ & 0 & $1(1.9)$ & $7(0.7)$ \\
\hline Ureteral injury & 0 & $1(0.3)$ & 0 & 0 & $1(0.1)$ \\
\hline Bleeding requiring re-operation & $9(1.4)$ & $2(0.7)$ & 0 & 0 & $11(1.1)$ \\
\hline Minor complications & $4(0.6)$ & $9(3.1)$ & 0 & $2(3.7)$ & $15(1.4)$ \\
\hline Anterior abdominal wall hematoma & $3(0.5)$ & 0 & 0 & 0 & $3(0.3)$ \\
\hline Vaginal cuff cellulites & 0 & 0 & 0 & $1(1.9)$ & $1(0.1)$ \\
\hline Vaginal cuff bleeding & $1(0.1)$ & 0 & 0 & $1(1.9)$ & $2(0.2)$ \\
\hline Surgical wound infection & 0 & $8(2.8)$ & 0 & 0 & $8(0.7)$ \\
\hline Surgical wound bleeding & 0 & $1(0.3)$ & 0 & 0 & $1(0.1)$ \\
\hline Total complications & $\mathbf{1 8 ( 2 . 8 )}$ & $\mathbf{1 3 ( 4 . 4 )}$ & $\mathbf{0}$ & $\mathbf{3 ( 5 . 6 )}$ & $\mathbf{3 4}(\mathbf{3 . 3})$ \\
\hline
\end{tabular}

Abbreviations: $\mathrm{LH}=$ laparoscopic hysterectomy; $\mathrm{TAH}=$ total abdominal hysterectomy; $\mathrm{TVH}=$ total vaginal hysterectomy; $\mathrm{RAH}=$ robotic-assisted hysterectomy 


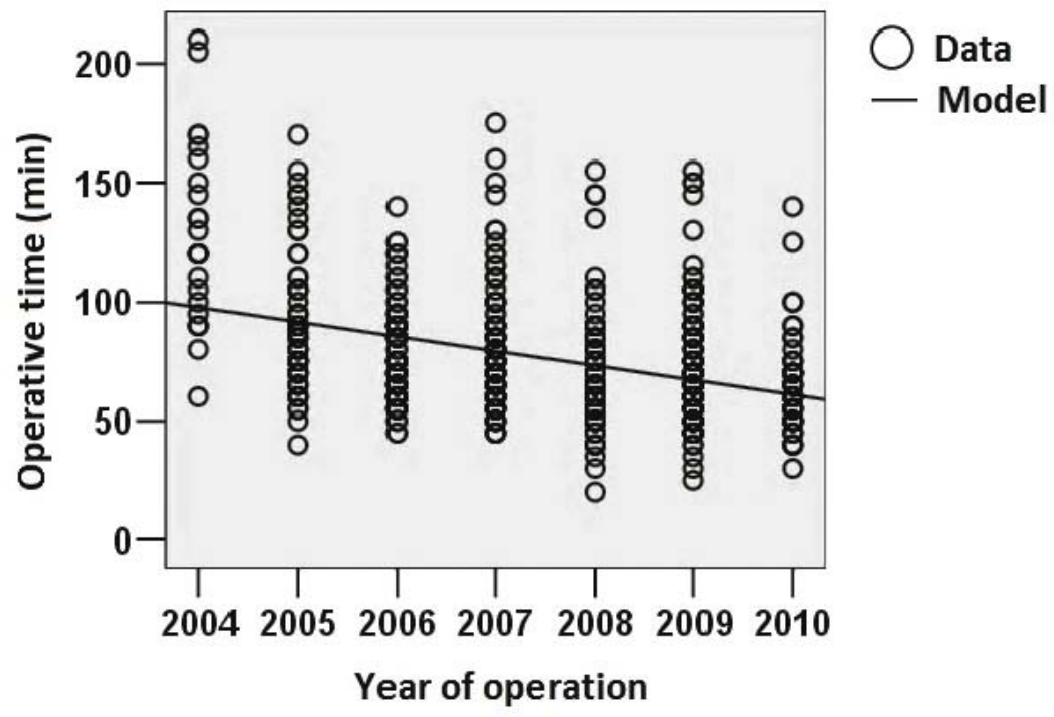

Figure 1. Regression analysis for linear correlation between the operative time and the year of operations for patients who underwent laparoscopic hysterectomies $(n=635)$.

\section{Discussion}

In most of the published literature (both retrospective and prospective randomized studies) two or three surgical approaches for hysterectomy are compared, e.g. laparoscopic vs. abdominal, laparoscopic vs. vaginal, abdominal vs. vaginal, or laparoscopic, vaginal and abdominal [17-25]. Fewer studies have analyzed complex perioperative factors of the four surgical types of hysterectomies, i.e. laparoscopic, abdominal, vaginal, and robotic $[5,6,11,26]$. The emphasis in two of the retrospective studies were cost analysis, and in one of them, histologic artifacts in hysterectomy specimens $[5,6,26]$. Landeen et al. focused on the perioperative parameters of RAH, the largest group of cases in their study $(n=569)$ [5]. The design of our study was similar to that of Smorgick et al. [11]. In their study, they examined retrospectively the experience of a 6-year period of hysterectomy patients and the surgical characteristics of 623 patients, operated on by three surgeons at a single institution. In the present study, we investigated the differences in the perioperative characteristics of four types of simple hysterectomies (i.e. LH, TAH, RAH, and TVH), performed at a single institution because of benign, pre-cancerous and early malignant gynecologic tumors during a 6-year period. The largest group included $\mathrm{LH}$ cases. We also compared three sub-types of hysterectomies within the LH group (i.e. LAVH, LH(a), and TLH).

Regarding the operative time, most of the studies indicate significantly longer operative time for LH cases in comparison with the abdominal and vaginal approach. However, there are several studies that did not find any significant difference [13, 23, 24, 27-29]. Most of the studies comparing LH with RAH reported that the mean operative time was significantly shorter in the LH group as compared to that in the RAH group [30-32]. In our study, the LH group of patients had a significantly shorter mean operative time as compared with the TAH and TVH groups. The LH group operative time was insignificantly shorter as compared to the RAH group.

The duration of an operative intervention is directly related to the severity of the operative trauma that the patient is exposed to. Therefore, the factors that can influence the operative time were analyzed. It is reasonable to assume that if a complication occurs, additional operative time will be required. The effect of both major and minor complications on the operative time was examined, as well as the incidence of complications in general. The mean operative time was significantly longer in the group with complications (93.9 $\pm 27.6 \mathrm{~min}$ ), as compared with the group with no complications $(76.1 \pm 26.4$ $\min )(p=0.002)$.

A surgeon's experience is usually associated with the number of operative interventions 
carried out, and the operative time is directly associated with this factor. The data from several studies indicated that after the first 30 laparoscopic hysterectomies, the operative time and incidence of complications were significantly reduced $[9,27,33]$. In the current study, we included all LH cases performed by the team during the investigated period and calculated the mean operative time for each calendar year. Regression analysis proved that the operative time decreased by six minutes per year on average $(p<0.001)$. (Figure 2$)$.

Hospital LOS is the principal parameter, influenced by the perioperative factors, e.g. "operative time, blood loss, time for recovery of the intestinal function, early post-operative complications" [34]. In our study, the mean hospital stay for the LH cases was significantly shorter (3.14 \pm 1.23 days) in comparison with the other types of hysterectomies - RAH $(3.76 \pm 1.68$ days), TAH (4.66 \pm 1.96 days), and TVH (5.29 \pm 1.42 days). Somewhat similar to our data are those reported by Wright et al. [6]. Our LOS results in the TAH cases are comparable to those reported by Vaisbuch et al. [27] and O'Hanlan et al. [29].

According to literature reports, the rate of complications in laparoscopic hysterectomy vary widely (from $0.3 \%$ to $19 \%$ ) $[9,35]$. No significant difference was found between the type of surgical approaches and the total rate of complications in our study $(p>0.05)$. The notable major complications requiring re-operation in our study included injury of the urinary tract, intestines, large vessels, and post-operative bleeding. This is understandable, since such complications can endanger the lives of the patients if the complication management approach is inadequate and untimely. Literature data are quite diverse. However, most studies reported are similar to ours, which means that the rate of these complications is significantly higher in LH than TAH groups $[4,9,13]$. Like Johnson et al, we found significantly lower frequency of the minor complications in the LH group in comparison with the TAH group $(p<0.05)$ and most were due to surgical wound infections [13].

Despite the large number of patients included in the present study, some limitations for the abatement of the statistical significance of the comparative analyses between the four methods of hysterectomy should be acknowledged. The non-randomized retrospective nature of the study is a potential reason for certain selection bias. The curve) is included in the group of minimallyinvasive hysterectomies, while the abdominal and vaginal hysterectomy group included operations with a well-mastered technique. The group of patients with vaginal hysterectomy was the largest, which is presumably a pre-requisite for better outcomes. The selection of surgical approach in hysterectomy and the surgeon's preferences obviously explain some of the differences in the patient characteristics.

\section{Conclusion}

The development of a mature gynecologic surgery program at our institution during the past several years evolved from a period of abdominal and vaginal hysterectomies to the period of contemporary MIS techniques for hysterectomies (i.e., laparoscopic and roboticassisted). The present comprehensive analysis provides insights into the current status of the surgical methods of hysterectomy at a single institution, driven by a number of specific circumstances, such as institutional, regional and national opportunities. Laparoscopic hysterectomy is an alternative to abdominal and vaginal hysterectomy. It is a safe minimally invasive surgical procedure leading to less operative trauma and faster recovery of patients when performed by a well-experienced surgical team. Prospective randomized multi-center studies would be desirable to further define the place of modern minimally invasive hysterectomy approaches.

\section{Acknowledgments}

The authors would like to thank Dr. Robert W. Holloway, MD, FACOG, FACS, Dr. Sarfraz Ahmad, PhD, FABAP, FACB and Dr. Zdravka Radionova, $\mathrm{MD}, \mathrm{PhD}$, for their logistic and

\section{References}

1. Semm K. Operationslehre fuer endoscopische abdominal Chirurgie. Operative Pelviscopie. Stuttgart; Schattauer; 1984.

2. Reich H, De Caprio J, McGlynn F. Laparoscopic hysterectomy. J Gynaecol Surg. 1989;5:213-6.

3. Garry R, Fountain J, Brown J, Manca A, Mason S, Sculpher M et al. EVALUATE hysterectomy trial: A multicenter randomized trial comparing 
abdominal, vaginal and laparoscopic methods of hysterectomy. Health Technol Assess. 2004;8(26):1-154.

4. Nieboer TE, Johnson N, Lethaby A, Tavender E, Curr E, Garry R, et al. Surgical approach to hysterectomy for benign gynaecological disease. Cochrane Database Syst Rev. 2009; (3):CD003677. doi: 10.1002/14651858. CD003677.pub4.

5. Landeen LB, Bell MC, Hubert HB, Bennis LY, Knutsen-Larson SS, Seshadri-Kreaden U. Clinical and cost comparisons for hysterectomy via abdominal, standard laparoscopic, vaginal and robot-assisted approaches. S D Med. 2011;64(6):197-9, 201, 203 passim.

6. Wright KN, Jonsdottir GM, Jorgensen S, Shah N, Einarsson JI. Cost and outcomes of abdominal, vaginal, laparoscopic and robotic hysterectomies. JSLS. 2012;16(4):519-24.

7. Jacoby VL, Autry A, Jacobson G, Domush R, Nakagawa S, Jacoby A. Nationwide use of laparoscopic hysterectomy compared with abdominal and vaginal approaches. Obstet Gynecol. 2009;114(5):1041-8.

8. Maresh MJ, Metcalfe MA, McPherson K, Overton C, Hall V, Hargreaves J, et al. The VALUE national hysterectomy study: description of the patients and their surgery. BJOG. 2002;109(3):302-12.

9. Mäkinen J, Johansson J, Tomás C, Tomás E, Heinonen PK, Laatikainen $T$ et al. Morbidity of 10110 hysterectomies by type of approach. Hum Reprod. 2001;16(7):1473-8.

10. Wu JM, Wechter ME, Geller EJ, Nguyen TV, Visco AG. Hysterectomy rates in the United States, 2003. Obstet Gynecol. 2007;110(5):1091-5.

11. Smorgick N, Patzkowsky KE, Hoffman MR, Advincula AP, Song AH, As-Sanie S. The increasing use of robot-assisted approach for hysterectomy results in decreasing rates of abdominal hysterectomy and traditional laparoscopic hysterectomy. Arch Gynecol Obstet. 2014;289(1):101-5.

12. Reich H, Roberts L. Laparoscopic hysterectomy in current gynecological practice. Rev Gynecol Pract. 2003;3(1):32-40.

13. Johnson N, Barlow D, Lethaby A, Tavender E, Curr L, Garry R. Methods of hysterectomy: Systematic review and meta-analysis of randomized controlled trials. BMJ. 2005;330(7506):1478.

14. Olive DL, Parker WH, Cooper JM, Levine RL. The AAGL classification system for hysterectomy. J Am Assoc Gynecol Laparosc. 2000;7(1):9-15.

15. Gortchev G, Tomov S, Tantchev L, Velkova A, Radionova Z. Da Vinci S robotic surgery in the treatment of benign and malignant gynecologic tumors. Gynecol Surg. 2010;7(2):153-7.

16. Rock JA, Jones HW, editors. TeLinde's Operative Gynecology. 9th ed. Philadelphia, PA: Lippincott Williams \& Wilkins; 2003.
17. Schutz K, Possover M, Merker A, Michels A, Schneider A. Prospective randomized comparison of laparoscopic-assisted vaginal hysterectomy (LAVH) with abdominal hysterectomy (AH) for treatment of the uterus weighing $>200 \mathrm{~g}$. Surg Endosc. 2002;16(1):121-5.

18. Seracchioli R, Venturoli S, Vianello F, Govoni F, Cantarelli M, Gualerzi B, et al. Total laparoscopic hysterectomy compared with abdominal hysterectomy in the presence of a large uterus. J Am Assoc Gynecol Laparosc. 2002;9(3):333-8.

19. Tsai EM, Chen HS, Long CY, Yang CH, Hsu SC, $\mathrm{Wu} \mathrm{CH}$, et al. Laparoscopically assisted vaginal hysterectomy versus total abdominal hysterectomy: A study of 100 cases on lightendorsed transvaginal section. Gynecol Obstet Invest. 2003;55(2):105-9.

20. Darai E, Soriano D, Kimata P, Laplace C, Lecuru F. Vaginal hysterectomy for enlarged uteri, with or without laparoscopic assistance: randomized study. Obstet Gynecol. 2001;97(5 Pt 1):712-6.

21. Soriano D, Goldstein A, Lecuru F, Darai E. Recovery from vaginal hysterectomy compared with laparoscopic-assisted hysterectomy: A prospective, randomized, multicenter study. Acta Obstet Gynecol Scand. 2001;80(4):337-41.

22. Benassi L, Rossi T, Kaihura CT, Ricci L, Bedocchi L, Galanti B, Vadora E. Abdominal or vaginal hysterectomy for enlarged uteri: A randomized clinical trial. Am J Obstet Gynecol. 2002;187(6):1561-5.

23. Müller A, Thiel FC, Renner SP, Winkler M, Häberle L, Beckmann MW. Hysterectomy - a comparison of approaches. Dtsch Arztebl Int. 2010;107(20):353-359.

24. Garry R, Fountain J, Mason S, Hawe J, Napp V, Abbott J, et al. The eVALuate study: Two parallel randomized trials, one comparing laparoscopic with abdominal hysterectomy, the other comparing laparoscopic with vaginal hysterectomy. BMJ. 2004;328(7432):129.

25. Ribeiro SC, Ribeiro RM, Santos NC, Pinotti JA. A randomized study of total abdominal, vaginal and laparoscopic hysterectomy. Int J Gynaecol Obstet. 2003;83(1):37-43.

26. Krizova A, Clarke BA, Bernardini MQ, James S, Kalloger SE, Boerner SL, et al. Histologic artifacts in abdominal, vaginal, laparoscopic, and robotic hysterectomy specimens: a blinded, retrospective review. Am J Surg Pathol. 2011;35(1):115-26.

27. Vaisbuch E, Goldchmit C, Ofer D, Agmon A, Hagay Z. Laparoscopic hysterectomy versus total abdominal hysterectomy: A comparative study. Eur J Obstet Gynecol Reprod Biol. 2006;126(2):234-8.

28. Gyr T, Ghezzi F, Arslanagic S, Leidi L, Pastorelli G, Franchi M. Minimal invasive laparoscopic hysterectomy with ultrasonic scalpel. Am J Surg. 2001;181(6):516-9. 
29. O'Hanlan KA, Huang GS, Garnier AC, Dibble SL, Reuland ML, Lopez L, et al. Total laparoscopic hysterectomy versus total abdominal hysterectomy: Cohort review of patients with uterine neoplasia. JSLS. 2005;9(3):277-86.

30. Cardenas-Goicoechea J, Adams S, Bhat SB, Randall TC. Surgical outcomes of robotic-assisted surgical staging for endometrial cancer are equivalent to traditional laparoscopic staging at a minimally invasive surgical center. Gynecol Oncol. 2010; 117(2): 224-8.

31. Giep BN, Giep HN, Hubert HB. Comparison of minimally invasive surgical approaches for hysterectomy at a community hospital: Roboticassisted laparoscopic hysterectomy, laparoscopicassisted vaginal hysterectomy and laparoscopic supracervical hysterectomy. J Robot Surg. 2010;4(3):167-75.

32. Nezhat C, Lavie O, Lemyre M, Gemer O, Bhagan L, Nezhat C. Laparoscopic hysterectomy with and without a robot: Stanford experience. JSLS. 2009;13(2):125-8.
33. Wattiez A, Joranio D, Cohen SB. The learning curve of total laparoscopic hysterectomy: Comperative analysis of 1647 cases. J Am Assoc Gynecol Laparosc. 2002;9(3):339-45.

34. Sesti F, Ruggeri V, Pietropolli A, Piccione E. Laparoscopically assisted vaginal hysterectomy versus vaginal hysterectomy for enlarged uterus. JSLS. 2008;12(3): 246-51.

35. Leonard F, Fotso A, Borghese B, Chopin N, Foulot H, Chapron C. Ureteral complications from laparoscopic hysterectomy indicated for benign uterine pathologies: A 13-year experience in a continuous series of 1300 patients. Hum Reprod. 2007;22(7):2006-11. 